\title{
Bi-axial fatigue analysis by stereo-correlation measurement
}

\author{
R. BRAULT ${ }^{1}$, T.DJILALI ${ }^{1}$, M. FAZZINI $^{2}$ and S.MISTOU ${ }^{2}$ \\ ${ }^{1}$ CRC Composites, 1 Rue Aristide Bergès, 65000 Tarbes, France \\ ${ }^{2}$ Université de Toulouse, INPT, ENIT, LGP, Avenue Azereix, BP1629, 65016 Tarbes Cedex
}

\begin{abstract}
This paper deals with the development of an experimental method to make measurements by the digital image correlation technique during a dynamic test on a biaxial tensile system. The aim of this method is to be able to cover a complete cycle of a dynamic test, regardless of its form and to follow a position during a long time test. Results are presented for different measurement fields.
\end{abstract}

\section{Introduction}

The digital images correlation technique (DIC) allows to having results in a large panel of test [1,2, 3, 4]. Some works have been made on elastomer properties identification by Mistou et al. [4, 5] where DIC performances are used for large deformation measurements. This technique was also implemented to improve the density of results in dynamic test, like vibration of thin wall during high speed machining [6] or for velocity measurement [7]. Secondly, the quality of the DIC technique is investigated in comparison with other optical methods regarding dynamic measurements [8]. These results exploit a high density of information given by the measurement system. Regarding the multiaxial tests, the optical methods are also interesting in their results on simultaneous multiple axis in damages or the identification of mechanical properties for cruciform specimens. [10, 11, 12]. If the DIC technique present many advantage, it is very important to determine the reliability of the testing procedure, especially the speckle pattern quality. In this optic, some studies have been made to improve the speckle pattern characterization $[3,13,14]$.

\section{Experimental setup}

The proposed method to make measurements during a fatigue test is only based on the experimental way. So here is a presentation of all experimental equipments used to provide results which are given in this paper.

\subsection{Bi-axial tensile system}

A biaxial tensile system is used to create the mechanical solicitation during the fatigue test. This machine is an Instron ${ }^{\circledR} 8800$ bi-axial. The capacity of this system is $100 \mathrm{kN}$ to each actuators and a frequency until $200 \mathrm{~Hz}$ with very small amplitudes. The configuration of the machine is a made for cruciform specimens, and there is no restriction for specimen material. The advantage with the Instron ${ }^{\circledR} 8800$ is the choice of working with two opposed actuators working together (Modal mode)

This is an Open Access article distributed under the terms of the Creative Commons Attribution-Noncommercial License 3.0, which permits unrestricted use, distribution, and reproduction in any noncommercial medium, provided the original work is properly cited. 
or not. In the modal mode, the software is set up to program a displacement on the deformation (no displacement of the center point) or the translation or the both for each axis of the test machine. Thus, there is a very large panel of possible cycle. The Figure 1 presents this bi-axial testing machine. For advanced applications, outputs are available to trigger external equipment on the system signals, like load, displacement, number of cycles. This functionality was very useful to work on the synchronization between various systems in this study.

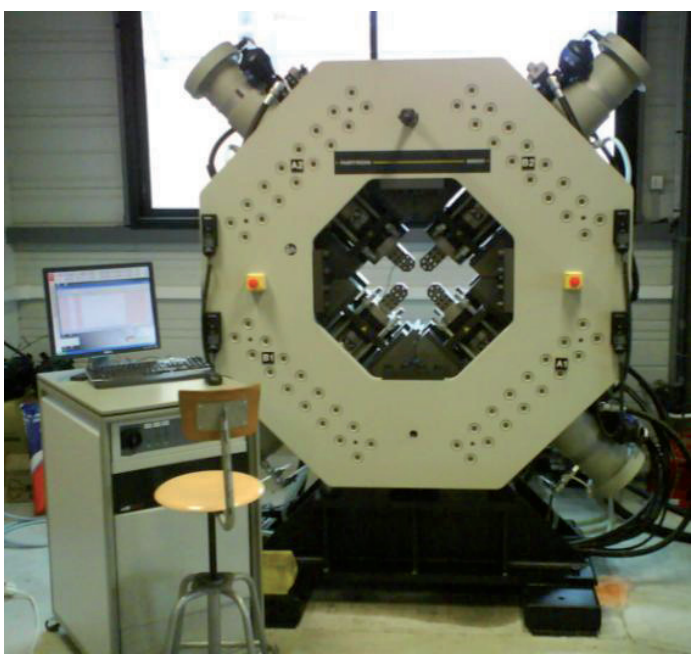

Fig. 1. Instron 8800 bi-axial fatigue tensile machine

\subsection{Lightening system}

Measurements during dynamic tests require specific equipment for the lightening. Indeed, it is necessary to provide sufficient light at the right moment to fix a position at a deformed state. For this study, the illumination is made by a stroboscope which can generate a flash until a $10 \mathrm{kHz}$ frequency. The stroboscope is trigged to the bi-axial test machine for the synchronization, which is managed by the Instron software. At a specific voltage level receive by the tensile machine, the stroboscope triggers a flash. This level is fixed arbitrary at $2.5 \mathrm{~V}$.

\subsection{Digital image correlation}

The digital image correlation equipment used is the GOM® ARAMIS [15] package included the ATOS® mobile system constitute of two digital cameras capable of shooting eight images per second, associated to the ARAMIS $®$ software, which make the correlation of numerical images and the computation of results. It consists in recording with two cameras some digital images of a specimen undergoing a deformation state (steps of a load cycle) and computing the image correlation by appropriate software. Before the test, a speckle is made on the specimen surface to allow the discretization of this surface in many correlation windows. For each step, the displacement of each correlation windows is calculated in relation with the previous step. This technique allows to determine the cartography of the displacement and the deformation during a test with a good accuracy. 


\section{Applications}

The following application is the support of this study. It is a fatigue test with a sinusoidal signal. There are several objectives to be achieved during this experiment. The major is to be able to determine the displacement at all positions on the sinus signal. Especially, it is interesting to follow the maximum displacement of the test at different times in the fatigue test.

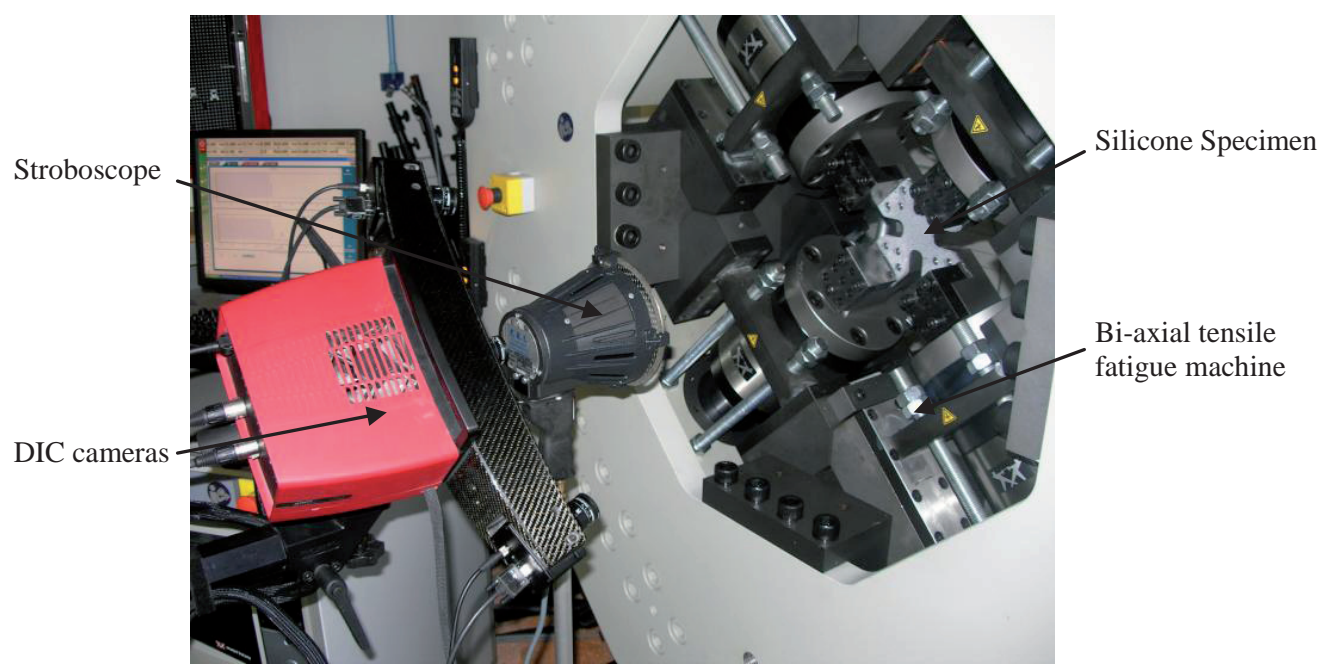

Fig. 2. Photo of experimental setup

\subsection{Specimens}

In order to exploit capacities of the DIC technique, we choose to work with a silicone specimen. It allows to easily having results in large deformation. The material is a RTV silicone with a 33 Shore A hardness. The design of this specimen is corresponding with the bi-axial cruciform tensile machine.

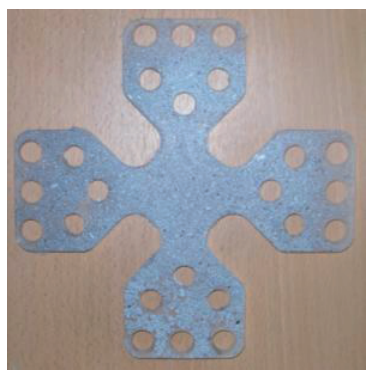

Fig. 3. Cruciform silicone specimen

\subsection{Speckle pattern characterization}

In order to anticipate the quality of correlation results, a works in relation with the speckle pattern characterization is made. Criteria are the grey value distribution and the average size of speckle. The tool used to study the quality of this speckle is a software developed by Fazzini [3] in the LGP laboratory called Autocorr. The Figure 4 and 5 respectively plot the grey value distribution and speckle size repartition. The major result of this work is the determination of the correlation window 
size, corresponding to 16.3 pixels. This value is based on the average radius of speckle, corresponding to the half height of the autocorrelation function.

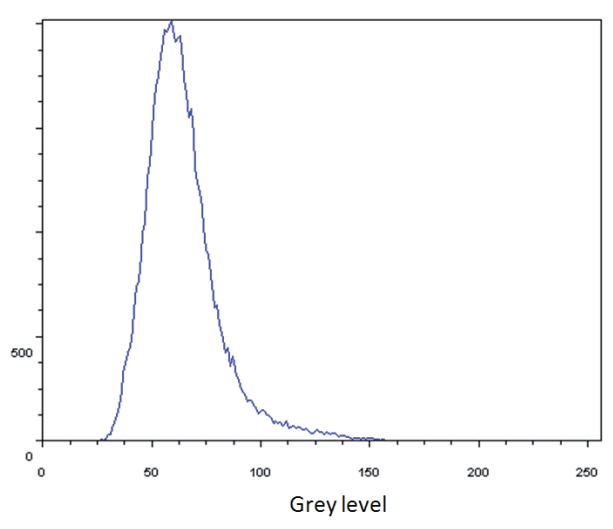

Fig. 4. Grey value distribution

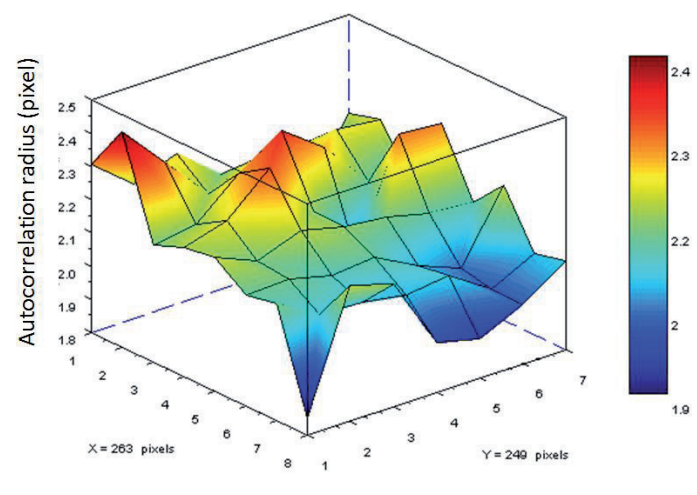

Fig. 5. Speckle radius repartition

Figure 4 show that images are mostly dark. The speckle pattern is manually made with black and grey paint sprays on initial white colour. Other, the speckle size is quite regular over the specimen surface, it is shown by the Figure 5 .

\subsection{Sinus cycle}

The signal used to make correlation test in fatigue is a sinusoidal form with $6 \mathrm{~mm}$ amplitude and 5 $\mathrm{Hz}$ frequency. This signal is an arbitrary choice and has no real physical signification, except the tensile solicitation of the silicone specimen. The graph of this sinus solicitation is shown on Figure 6.

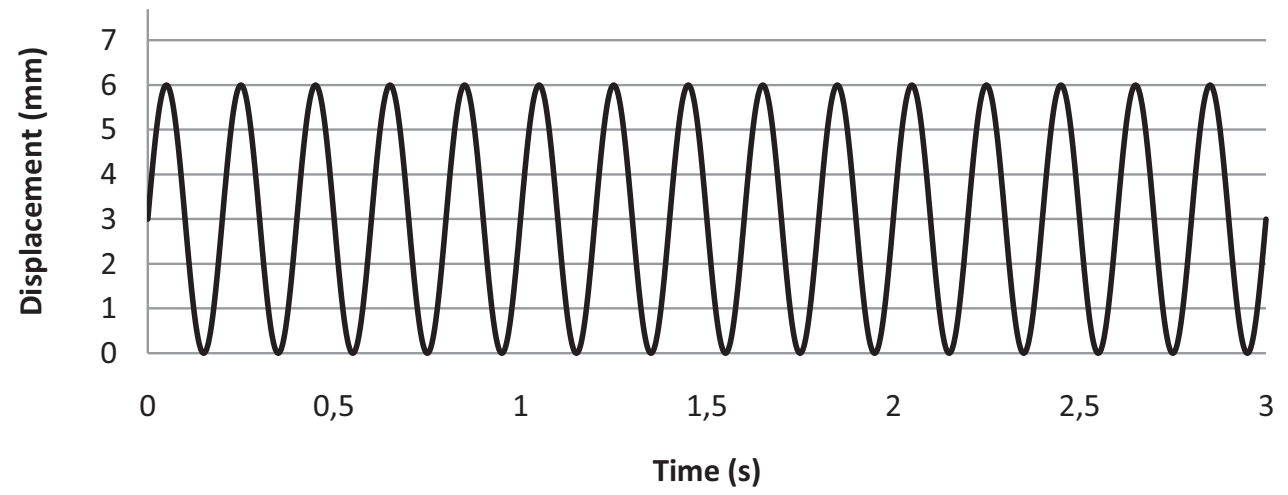

Fig. 6. Sinusoidal displacement cycle

\subsection{Synchronization}

The major problem to develop this method is to obtain the right synchronization between all equipments: DIC camera, stroboscope and bi-axial tensile machine. Where every system are connected and trigged, during the fatigue test, we observed a phase shift between the stroboscope flash and the maximum position on the sinus signal. The delay can be attributed to the transfer of 
data and their treatments. The Figure 7 describes the synchronization issue by the plot of different signals versus time.

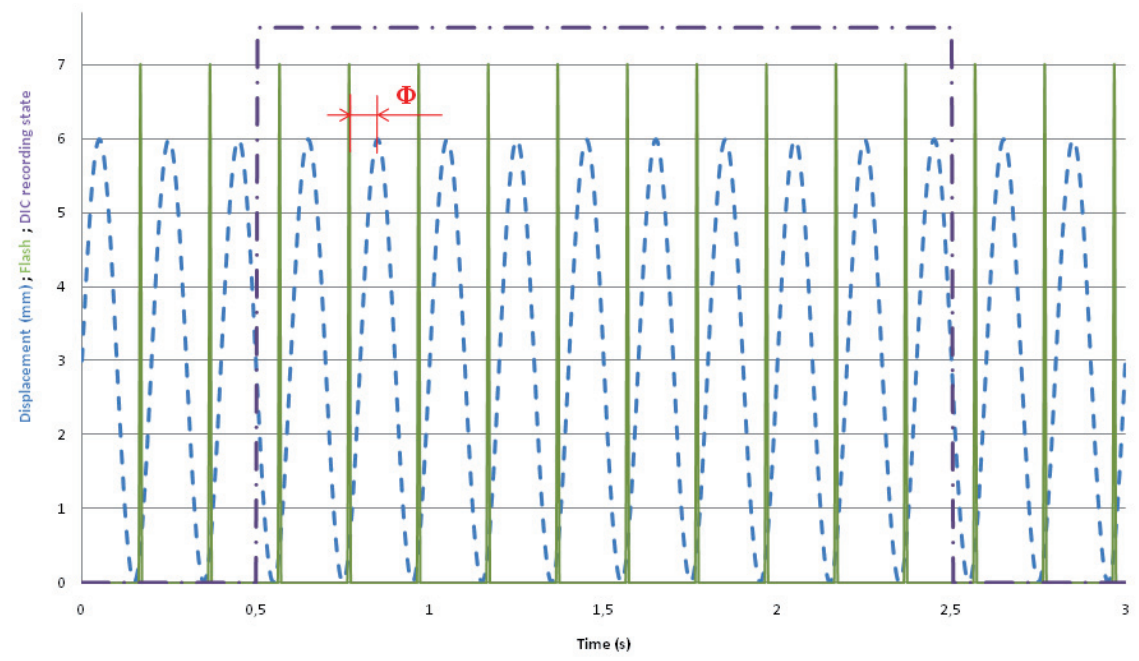

Fig. 7. Graph of synchronization issue

Both approaches have been discussed to have the right configuration. The first approach is the analogical way. Indeed, by the known of the stroboscope flash voltage level $S_{F}$, the full scale $S$ of the tensile machine output signal $(0 \mathrm{~V}-10 \mathrm{~V})$ and the maximum displacement $U_{\max }$, we are capable to determine the phase shift $\Phi$ between the flash time and the maximum position time, by the following equation.

$$
U_{\max }-\left(\frac{S \times S_{F}}{10}\right)=\sin [(\Phi+270)+1] \times \frac{U_{\max }}{2}
$$

This method provided approximate results very quickly. By the numerical application of the equation (1), the phase shift $\Phi$ between the flash and the maximum displacement was estimated at $156.4^{\circ}$.The second approach is an experimental evaluation of this phase shift. This method requires the integration of a numerical oscilloscope in the measurement loop, to receive two output signals: the tensile machine displacement and the stroboscope flash. Figure 8 presents a schema included all test equipments.

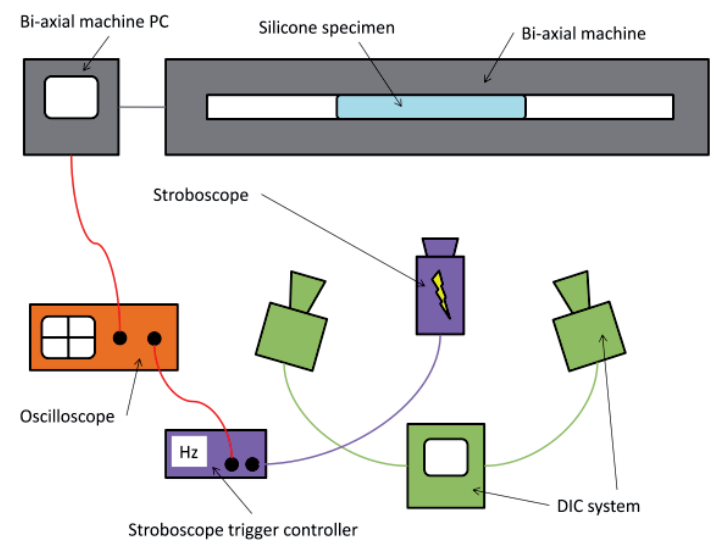

Fig. 8. Schema of experimental equipments for phase shift determination 
By the fitting of the maximum stroboscope signal, corresponding to the flash, on the maximum displacement, we ensure the right phase shift setting. $\Phi$ is set by the stroboscope trigger controller, indeed it is possible to put a phase shift from $0^{\circ}$ to $360^{\circ}$. The optimized value for the phase shift was determined at $116^{\circ}$ Thus, we are able to follow the maximum displacement $U_{\max }$ position during a fatigue test. The Figure 9 illustrates this result and shows that the technique used allows well to follow sinusoidal displacement.
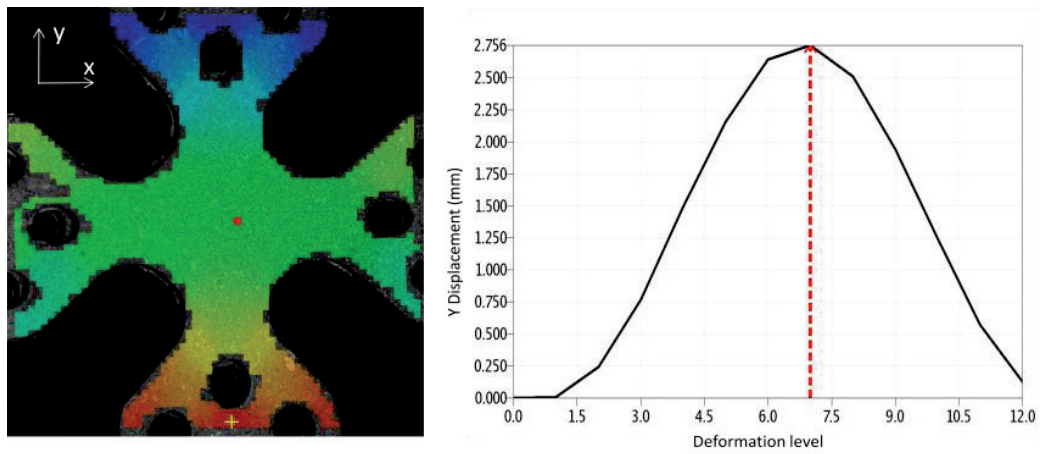

Fig. 9. Results of correlation with phase shift synchronization

\subsection{Results}

In order to validate the dynamic stereo-correlation method, here is a review of the different kind of results available after a fatigue test using a sinusoidal signal of $6 \mathrm{~mm}$ amplitude a $5 \mathrm{~Hz}$ frequency on a silicone cruciform specimen. Figure 10 show that the deformation value is completely available on all the specimen area. It is the same for displacement $\mathrm{X}, \mathrm{Y}$ and $\mathrm{Z}$, and Euclidean shown by Figure 11. The two last Figures 12 and 13 show the distribution of major deformation and $\mathrm{Z}$ displacement along a section of the specimen for each step of the testing cycle.
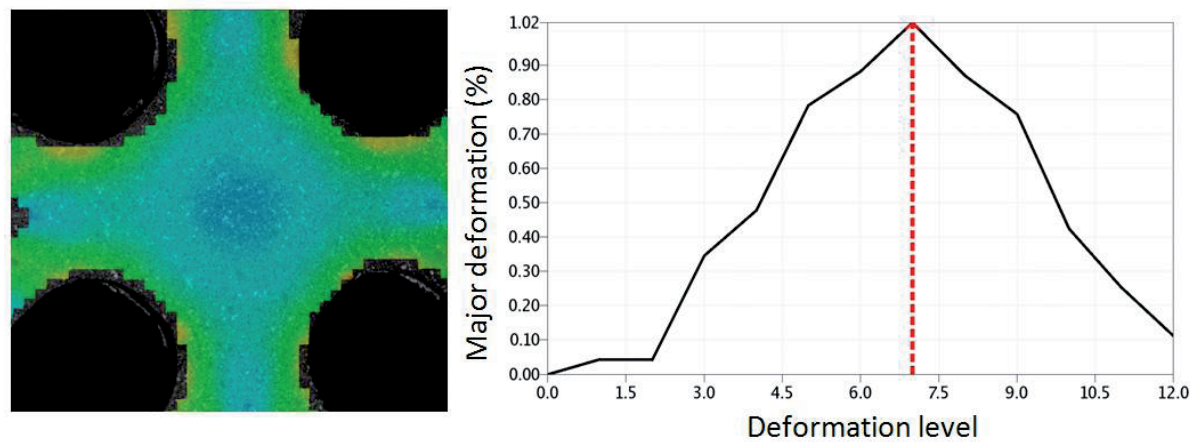

Fig. 10. Major deformation (\%) at the maximum amplitude 

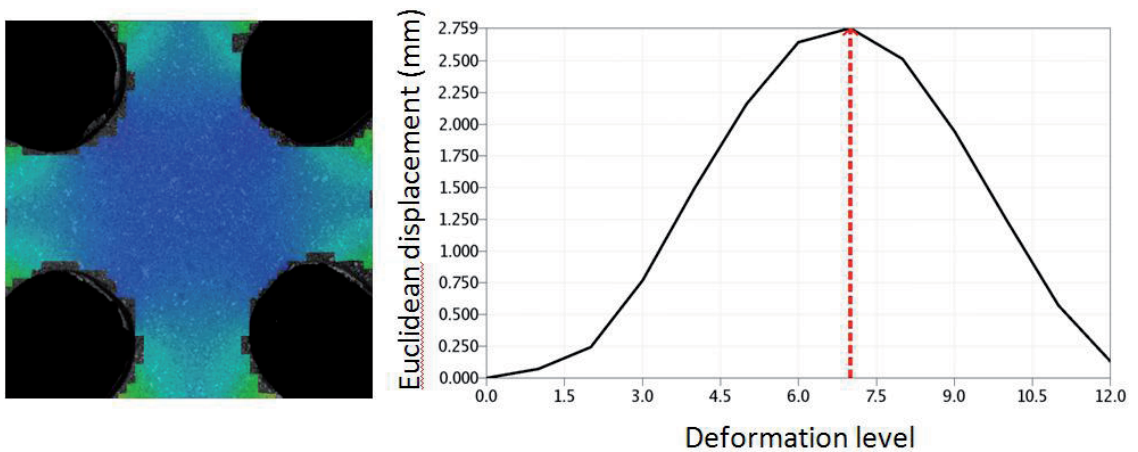

Fig. 11. Euclidean displacement $(\mathrm{mm})$ at the maximum amplitude
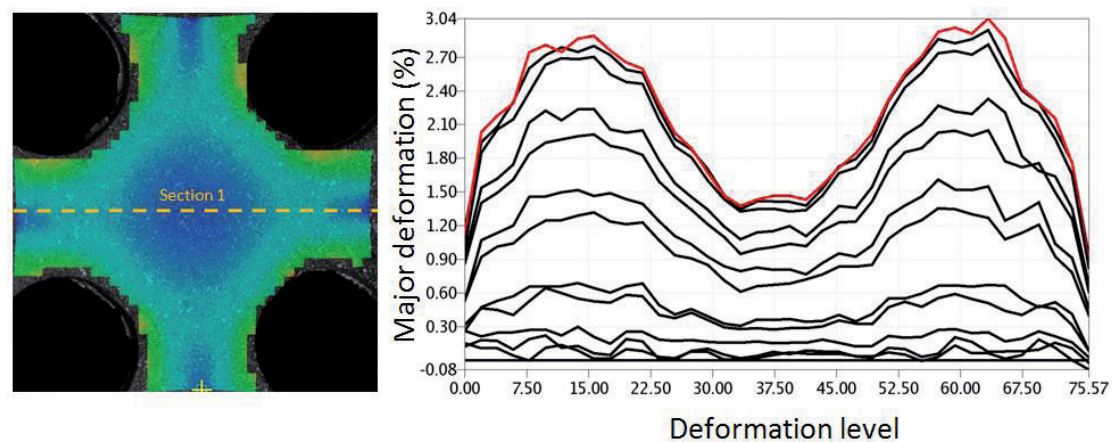

Fig. 12. Distribution of major deformation (\%) along Section 1
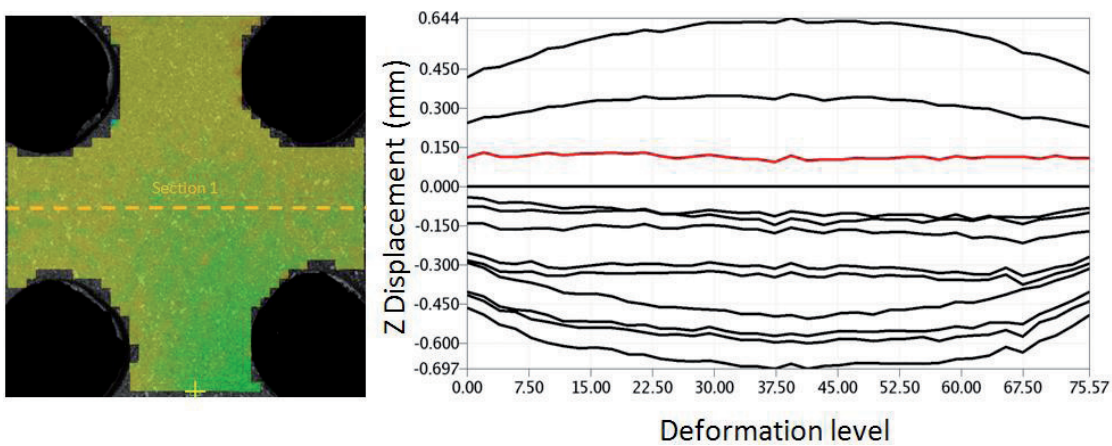

Fig. 13. Distribution of out of plane $\mathrm{Z}$ displacement (mm) along Section 1

\section{Conclusions}

An experimental method has been developed to make displacement and deformation measurements with the DIC technique during a dynamic sinusoidal fatigue test. This method uses the capacity of stereo correlation equipment to be trigger on a bi-axial tensile machine. A stroboscopic light was used to be able to make measurements at a very accurate position on a sinusoidal displacement. A work was made on the synchronization between DIC software, tensile machine and stroboscope, to determine the phase shift imposed on the stroboscope flash to make measurements at the good cycle 
position. Thus, the following of the maximum position, or any other, during a very long time test is possible. Perspectives of this study are the determination of fatigue life properties of a specimen with a bi-axial solicitation. The quality of DIC results will be very useful to create a numerical model and to correlate it with these experimental results.

\section{References}

1. M. Bornert, F. Brémand, P. Doumalin, J.C. Dupré, M. Fazzini, M. Grédiac, F. Hild, S. Mistou, J. Molimard, J.J. Orteu, L. Robert, Y. Surrel, P. Vacher \& B. Wattrisse. Assessment of Digital Image Correlation software packages. Experimental Mechanics, vol. 49(3), pages 353_370 (2009)

2. D. Garcia \& J.-J. Orteu. 3D Deformation Measurement using Stereo-correlation applied to experimental Mechanics. Proceeding of 10th FIG International Symposium on Deformation Measurements, Orange, California (2001)

3. M. Fazzini, Développement de méthodes d'intégration des mesures de champs, Thèse de doctorat, Ecole Nationale d'Ingénieurs de Tarbes (2009)

4. M. Fazzini, S. Mistou, M. Karama, B. Desmars \& P. Peres. Identification of elastomers by Digital Image Correlation. 5th European Conference On Constitutive Models for Rubber (ECCMR) (2007)

5. S. Mistou, M. Karama, B. Desmars, P. Peres, E. Piron \& P. Heuillet. Application de la méthode de stéréocorrélation d'images à la caractérisation des élastomères en grandes déformations. Photomécanique, vol. 4, pages 147-166 (2004)

6. M. Fazzini, T. Wehbe, G. Dessein, L. Arnaud \& S. Seguy. Stéréocorrélation d'image : Application aux vibrations d'une paroi mince en usinage. Colloque Méthodes et Techniques Optiques pour l'Industrie, CMOI (2007)

7. E.B. Li, A.K. Tieu, W.Y.D. Yuen, Application of digital image correlation technique to dynamic measurement of the velocity field in the deformation zone in cold rolling, Optics and Lasers in Engineering, vol 39, pages 479-488 (2003)

8. T. Schmidt, J. Tyson \& K. Galanulis. Full-Field Dynamic Displacement and Strain measurement using advanced 3D image correlation photogrammetry. Experimental Techniques, vol. 27, no. 3, pages 47-50 (2003)

9. S.Vanlanduit, J.Vanherzeele, R.Longo, P. Guillaume, A digital image correlation method for fatigue test experiments Optics and Lasers in Engineering, vol 47, pages 371-378 (2009)

10. D. Lecompte, A. Smits, H. Sol, J. Vantomme \& D. Van Hemelrijck. Mixed numericalexperimental technique for orthotropic parameter identi_cation using biaxial tensile tests on cruciform specimens. International Journal of Solids and Structures, vol. 44, pages 643_1656 (2007)

11. JN. Périé, S. Calloch, C. Cluzel \& F. Hild. Analysis of a multiaxial test on a C/C composite by using digital image correlation and a damage model. Experimental Mechanics, vol. 42, no. 3, pages 318-328 (2002)

12. F. Abbassi, I. Elfaleh, M. Fezzani, S. Mistou et Ali Zghal, Mise en forme de plaques composites carbone-PPS, Comptes Rendus des JNC 16, Toulouse (2009)

13. D. Lecompte, A. Smits, Sven Bossuyt, H. Sol, J. Vantomme, D. Van Hemelrijck, A.M. Habraken, Quality assessment of speckle patterns for digital image correlation, Optics and Lasers in Engineering, vol. 44 1132-1145 (2006)

14. L. Robert and Workgroup "Metrology" of CNRS research network 2519 "MCIMS, Estimation of digital image correlation (DIC) performances, Experimental Analysis of Nano and Engineering Materials and Structures Proceedings of the 13th International Conference on Experimental Mechanics, Alexandroupolis, Greece, July 1-6, (2007)

15. Aramis software. GOM Optical Measuring Techniques, http//www.gom.com/EN/index.html, (2006) 